\title{
State Estimation in Posterior Parietal Cortex: Distinct Poles of Environmental and Bodily States
}

\author{
W. Pieter Medendorp ${ }^{1, \#, *}$, Tobias Heed ${ }^{2,3, \#^{*}}$ \\ ${ }^{1}$ Radboud University, Donders Institute for Brain, Cognition and Behaviour, Nijmegen, The Netherlands \\ ${ }^{2}$ Biopsychology \& Cognitive Neuroscience, Faculty of Psychology \& Sports Science, Bielefeld University, Bielefeld, Germany \\ ${ }^{3}$ Center of Excellence in Cognitive Interaction Technology (CITEC), Bielefeld University, Bielefeld, Germany \\ \# The authors contributed equally. \\ * Correspondence: \\ p.medendorp@donders.ru.nl (W.P. Medendorp), Postbus 9104, 6500 HE Nijmegen, The Netherlands
}

Keywords: effector specificity; sensorimotor processing; state estimation; cortical organization; body schema

Posterior parietal cortex (PPC) has been implicated in sensory and motor processing, but its underlying organization is still debated. Sensory-based accounts suggest that PPC is mainly involved in attentional selection and multisensory integration, serving novelty detection and information seeking. Motorspecific accounts suggest a parietal subdivision into lower-dimensional, effector-specific subspaces for planning motor action. More recently, function-based interpretations have been put forward based on coordinated responses across multiple effectors evoked by circumscribed PPC regions. In this review, we posit that an overarching interpretation of PPC's functional organization must integrate, rather than contrast, these various accounts of PPC. We propose that PPC's main role is that of a state estimator, which extends into two poles: a rostral, body-related pole, which projects the environment onto the body and a caudal, environment-related pole that projects the body into an environment landscape. The combined topology interweaves perceptual, motor, and function-specific principles, and suggests that actions are specified by top-down guided optimization of body-environment interactions.

\section{Current ideas about the driving forces of posterior parietal cortical organization}

Posterior parietal cortex (PPC) is usually described as a sensorimotor interface, acknowledging its two dominant roles: to merge information from multiple senses such as vision, based on transformations of, and associations with, this sensory input. However, the underlying function of PPC, as well as the factors driving its large-scale organization, are still hotly debated (Caminiti et al., 2010; Fattori et al., 2015; Huntenburg et al., 2018; Mars et al., 2018, 2011; Vallar and Coslett, 2018; $\mathrm{Xu}, 2018)$. Although serial accounts of cognitive function have long proven inadequate, and the inseparability of sensory and motor processing is now widely acknowledged, many research programmes have pitted the "sensory" and "motor" in "sensorimotor" against each other. Accordingly, different research directions have scrutinized PPC organization each with a particular set of questions in mind. Interpretation of experimental results is restricted by the applied manipulations and controls (Krakauer et al., 2017), often emerging as quasi consensus within a (sub-) field.

Here, we promote rethinking PPC organization with the notion that sensory and motor function are inseparable, and that an overarching account of PPC organization must take on a perspective that embraces their interaction. We propose that PPC is best understood when viewed from an angle that accentuates estimating the state of the body relative to the environment and, vice versa, the state of the environment relative to the body. This view embraces the integrative, sensorimotor role of PPC (Gottlieb, 2007; Gottlieb and Balan, 2010; Siegel et al., 2015; Snyder, 2000a), its role of continually defining the best next action, and of supervising its execution in a sensorimotor control loop (Cisek and Kalaska, 2010; Pezzulo and Cisek, 2016).

\subsection{Sensory-based accounts of PPC organization}

Sensory-based accounts suggest that PPC is mainly involved in attentional selection (Bisley and Mirpour, 2019) and (multi-)sensory integration (Rohe and Noppeney, 2016) serving the detection of novelty, guiding curiosity-driven behavior, and aiding information seeking (Gottlieb, Oudeyer, Lopes, \& Baranes, 2013). Fitting this notion, PPC displays a rostral-to-caudal organizational gradient from somatosensory to visual dominance, as might be expected given the locations of the respective primary sensory regions. For example, area 5 in the rostral portion of PPC features a somatosensory homunculus similar to its neighboring primary somatosensory cortex (Penfield and Boldrey, 1937; Roux et al., 2018), with notable magnification of the body parts that are most relevant to a given species (Seelke et al., 2011; Taoka et al., 1998). Slightly more caudal, monkey ventral intraparietal area (VIP), and an analogous region in humans, 
contain head-centered tactile maps that overlap, or are interspersed with, visual maps for looming stimuli (Cléry et al., 2017; Guipponi et al., 2013; Huang et al., 2012; Sereno and Huang, 2014). The same portion of PPC also processes sensory inputs related to heading direction, such as visual flow and vestibular signals (Chen, DeAngelis, \& Angelaki, 2013; Drugowitsch, DeAngelis, Klier, Angelaki, \& Pouget, 2014; Fetsch, DeAngelis, \& Angelaki, 2013), further stressing its role in multisensory integration. Yet, multiple visual maps extend all the way to occipital cortex, presumably reflecting higher cognitive functionality the further they extend into PPC (Szczepanski et al., 2013).

\subsection{Effector-based accounts of PPC organization}

Strict sensory-based accounts of PPC organization are challenged by findings that suggest local specialization related to movement of specific effectors (Andersen and Cui, 2009; Grefkes and Fink, 2005; Kastner et al., 2017; Snyder, 2000b; Vesia and Crawford, 2012). Numerous electrophysiological studies in non-human primates have suggested that the lateral intraparietal area (LIP) encodes eye movement plans, whereas the parietal reach region (PRR), which contains the medial intraparietal area (MIP), is responsive to impending reaches (Andersen and Cui, 2009). Likewise, transcranial magnetic stimulation (TMS) over human PPC can cause selective impairments of saccade and reach planning (Vesia et al., 2010a, 2010b). Human fMRI studies have shown that PPC contains multiple maps specific to saccades, hand pointing, or hand reach direction (Hagler Jr. et al., 2007; Kastner et al., 2017; Konen and Kastner, 2008; Gallivan et al., 2011; Leoné et al., 2014b). When participants plan movements towards the location opposite to an instructional cue, PPC initially codes sensory information, but motor-related information thereafter (Gail and Andersen, 2006; Medendorp et al., 2005; Zhang and Barash, 2000). PPC also represents the task rule, that is whether movements are to be directed towards or away from the cue (Connolly et al., 2000; Fernandez-Ruiz et al., 2007; Gail and Andersen, 2006; Klaes et al., 2011). These findings are at odds with a purely perceptual-attentional account of PPC and implicate a role in mediating sensorimotor transformations.

Extending this work, several human $\mathrm{fMRI}$ studies have suggested an rostral-to-caudal gradient for limb movements vs. saccades as one organizing principle of PPC (Beurze et al., 2009; Burnod et al., 1999; Caminiti et al., 2010; Heed et al., 2011, 2016 b). This gradient may seem intuitive with respect to the rostral-to-caudal gradient relating to touch vs. vision, with vision and saccadic movements both occupying caudal regions. Note, however, that this match is by no means self- evident, since both hand reaches and saccades can obviously be made to both visual and tactile targets. Thus, the observed gradient seems to depend on the consequences that result from the respective type of movement: saccades have predominately visual consequences; limb movements have predominately proprioceptive and tactile consequences, and will often require further motor commands, for instance when correcting the trajectory of the moved limb, or to adjust other body parts to regain balance.

\subsection{Challenges for an effector-specific account of PPC organization}

\subsubsection{Incomplete separation of eye and hand processing}

The notion of effector specificity has led to the view that, in analogy to the somatotopic organization of primary somatosensory cortex, PPC is subdivided into lower-dimensional, effectorspecific subspaces which define the current movement goal in relation to a specific effector (Andersen and Cui, 2009). Yet, in monkeys, both LIP and PRR also house neurons that are responsive the non-preferred effector (Oristaglio et al., 2006; Snyder et al., 2000, 1997), and many human fMRI studies have emphasized considerable activation overlap in areas active for eye and hand movements (Hagler Jr. et al., 2007; Hinkley et al., 2009; Gallivan et al., 2011). Moreover, not all PPC regions fit easily into an effector-based scheme. For example, VIP houses neurons with visual, tactile, and auditory receptive fields (RFs) around the animal's body, while its motor role is associated with defensive movements involving a diversity of body parts, such as flinching, fletching the teeth, turning the head, and hiding the arm (Graziano and Cooke, 2006). Similar observations were made in the anterior intraparietal area (AIP) (Zhang et al. Neuron, 2017); this area was traditionally believed to code for hand shape and grasping, but was recently reported to carry also signals related to both hands as well the shoulder in humans (Menz et al., 2015).

With the widely applied comparison of hand and eye movements, experiments supporting effectorbased accounts have heavily relied on functionally vastly different systems. Whereas fingers and hands interact with the environment, the eyes serve perceptual rather than manipulative functions and are tightly linked to attentional processing (Corbetta et al., 1998). Also from a kinematics perspective, the spatial transformations needed to direct the hand to a visual target are entirely different than those required for eye movements (Crawford et al., 2011). Thus, ultimately neither differences nor similarities between eye and hand movements 
offer a complete picture about the large-scale organization of the parietal cortex.

Some studies have compared movements of the two arms (Beurze et al., 2007; Calton et al., 2002; Chang et al., 2008; Gallivan et al., 2013; Medendorp et al., 2005; Valyear and Frey, 2015). However, this approach suffers from the drawback that each arm is primarily controlled by the contralateral hemisphere, so that any differences in processing of the two limbs may be due to body symmetry rather than effector specificity.

\subsubsection{Different effectors, similar parietal cortical activity}

Like the hand, the foot can manipulate objects; and comparing activity for the limbs of one body side allows comparing effector-specific organization within one hemisphere. Currently, monkey data about goal-directed foot movements are not available. However, using fMRI, we have addressed the topic of large-scale organization of human PPC with a goal-directed pointing task with right hand, right foot, and the eyes.

In a first study, we observed a caudo-rostral gradient from eye to limb movement planning, but, importantly, no segregation between foot and hand movement planning along the IPS (Heed et al., 2011). Only in rostral parts of PPC, adjacent to S1, there was a coarse, lateral-to-medial gradient for hand vs. foot planning, with overlapping hand and foot activation between more effector-specific activation swaths. Consistent with this result, others have shown that rhythmic ankle, finger, and elbow movements elicit largely overlapping fMRI activation along medial IPS, whereas effectorspecific activation was evident in rostral PPC, laterally for the finger and medially for the ankle (Cunningham et al. 2013).

Using multivariate, multi-voxel pattern analysis of a completely new participant sample of the goaldirected pointing task, we confirmed the limb generality of caudal PPC regions, and further suggested that many of the more rostral regions distinguished one from the other two effectors (Leoné et al., 2014a): regions that responded predominately for one effector also held a common representation for the other two effectors. Together, these studies challenge a strict effector-specify view of PPC.

While multivariate approaches decode information across voxels in a region, they cannot distinguish the fine-grained neural organization within a given fMRI voxel: For regions that are active for several effectors, is movement planning for each respective effector mediated by separate neurons, or by a common neuron pool? FMRI repetition suppression (RS) approaches interpret BOLD signal reductions from one trial to the next as an indicator of overlapping neuron pools across trials (GrillSpector and Malach, 2001; Valyear et al., 2012). In an RS version of the hand, foot, and eye pointing task (Heed et al., 2016b), RS patterns suggested that a common neuronal pool mediates planning for all three effectors in caudal PPC, though with a bias for saccades in putative human LIP (Grefkes \& Fink, 2005; Kastner et al., 2017). In rostral PPC, most regions showed RS patterns consistent with neuronal selectivity for either hand (laterally) or foot (medially), with the exception of one region between hand and foot regions whose neurons showed RS for both limbs, but not the eyes (Heed et al., 2016b). This activity pattern is generally consistent with segregated neuronal responses in area 5 of monkeys (Taoka et al., 2000, 1998), but notably also with a monkey region in rostral PPC responding to both limbs (Bakola et al., 2010; Breveglieri et al., 2008).

\subsection{Functional aspects of PPC organization}

1.4.1 Functionally determined activation during observation and imagery

The MRI environment places strong constraints on paradigms that involve overt movement. However, many motor regions exhibit activity not only when participants plan movements, but also when they either observe another individual making movements on video (Abdollahi et al., 2013; Cattaneo and Rizzolatti, 2009; Filimon et al., 2007; Hardwick et al., 2018), or when they imagine, rather than actually perform, motor actions (Bakker et al., 2008; Filimon et al., 2007; Hardwick et al., 2018; Lorey et al., 2014; Vingerhoets, 2014). Action observation and motor imagery studies can, therefore, be informative about the neural organization of PPC (Aflalo et al., 2015; Klaes et al., 2015). When observers saw video clips of four different motor actions - dragging, dropping, grasping, and pushing - performed with either hand, foot, or mouth, PPC activation clustered according to the type of action, regardless of the employed effector (Jastorff et al., 2010). Consistent with this observation, the excitability of the primary hand motor area was enhanced by observing actions typically performed by the hand, even when those actions were performed with the foot; conversely, the excitability of the primary foot motor area was enhanced by viewing a typical foot action, independent of the effector actually being used in the observed (Senna et al., 2014). Another study compared observation of manipulation, locomotion and climbing (Abdollahi et al., 2013). Because climbing involves the same effectors as hand manipulation and locomotion combined, the authors reasoned that similar activations should be evident if PPC were organized in an effector-specific manner. However, the three action categories activated distinct regions in PPC, inconsistent with an effectorspecificity account, and more consistent with a 
functional organization of PPC. Findings of imagery studies further support the conclusions of movement planning and movement observation studies. Although some differences were observed in a direct comparison of observation and imagery, activation with both kinds of paradigm showed stronger differences for different types of actions than for different effectors (Lorey et al., 2014).

In sum, common organizational principles of PPC emerge across versatile experimental approaches ranging from self-performed simple pointing and flexion movements to observation and imagination of complex whole-body movement. They do not prominently feature effector specificity as a major source of regional specialization within PPC; instead, they promote the importance of functional criteria, such as categories of actions.

\subsubsection{Ecologically relevant action classes revealed} by cortical stimulation

Electrical stimulation and optical imaging of PPC in several primate species have suggested that different regions of PPC, each connected to specialized premotor regions, mediate distinct functional classes of ecologically relevant movements, such as hand-to-mouth feeding, reaching, coordinated movements with all four limbs, and self-defense (Stepniewska et al., 2005, 2011; Baldwin et al., 2016; Graziano, 2016; Graziano and Aflalo, 2007). Like the human fMRI work, these results argue against an organization that represents individual effectors, and instead suggest that specialized regions elicit control of all effectors relevant for the respective movement class. This concept of action representation implies that the PPC is organized to initiate several classes of ethologically relevant behaviors, based on sensory and intrinsic signals, and mediated via connections of PPC with premotor and motor cortex (Mars et al., 2018, 2011; Orban, 2016; Stepniewska et al., 2011). Many typical actions involve the coordination of multiple effectors, and regional overlap for different effectors, therefore, appears instrumental for resolving the challenge that many redundant actions could solve a given task. This notion is in line with previous suggestions that entertaining separate machinery for coding similar planned movements that only differ in the effector used to execute them is computationally inefficient (Levy et al., 2007). In fact, single neuron activity in the anterior intraparietal area of a tetraplegic patient has been reported to code many variables, including body part, body side, and task characteristics, within the same neuronal population (Zhang et al., 2017). However, although the neuronal population coded for all tested body parts, neural coding was independent between them. This type of mixed neural coding (Fusi et al., 2016) could be at the heart of an effectoroverarching, functional organization.

\section{Towards an integrated view of PPC: Optimal Feedback Control}

The different accounts of PPC organization perception vs. action, somatosensory vs. visual processing, effectors vs. action classes demonstrate that the proposed lawful solutions to the underdetermined, multidimensional problem of organizing PPC into a two-dimensional neuronal matrix much depend on the focus of the research question and the involved task paradigms. Viewed this way, depending on how one cuts through the hyperspace of solutions implemented by the PPC, each specific account could serve as a governing principle, perhaps to support the whole brain for achieving optimal performance. The traditional approach of contrasting perceptual with actionrelated, motor function has led to seemingly incompatible solutions to the PPC puzzle. We posit that understanding the overarching functional organization of PPC will require integrating, rather than contrasting, these views of brain function. In serving this overall goal, optimal feedback control (OFC) theory (Todorov, 2004), which is a prominent theory in motor control, suggests that sensation and movement are merely inseparable aspects of an action control loop. Taking this view can shed new light on the debate about the role of the PPC: rather than segregating sensory and motor roles, it suggests to inquire about the overarching purpose and principles of sensorimotor integration.

In the OFC framework, the brain must continually estimate both the state of the environment and the state of the body and combine the two to elicit and control adequate behavior. In this process of state estimation, the brain relies on sensory input as well as on predictions of sensory inputs based on outputs of forward internal models, which represent the mapping between motor commands and their effect on the body in the world (Oostwoud Wijdenes and Medendorp, 2017; Scott, 2012; Shadmehr and Krakauer, 2008). There is indeed evidence that that PPC activity predicts the sensory consequences of upcoming movements (Mulliken et al., 2008; Pilacinski et al., 2018; Sirigu et al., 1996).

Here, we extend this view and propose that it is possible to subsume the discussed organizational principles of PPC under a common roof of state estimation. In particular, we suggest that state estimation organizes the PPC into a rostral, bodyrelated pole, and a caudal, environment-related pole. Thus, while in OFC models and its simulations, the various state variables are represented by a single state vector that is estimated and updated when the movement unfolds and/or the environment changes (Diedrichsen et al., 2010; Schwartz, 2016; Shadmehr and Krakauer, 2008), we propose that this vector is cortically mapped along the rostral-to-caudal axis of PPC layout. 
2.1 A rostral-to-caudal gradient for state estimation: body vs. environment

In our framework, caudal PPC represents an environmental landscape and projects the body in relation to that landscape, so that it can be associated to other objects in the environment. This function explains the predominance of visual, or more generally external-spatial, processing, with vision providing information of even far distant objects and events for which current body posture is of no or little relevance. Furthermore, for objects and events near the body, caudal PPC relates non-visual to visual information to code the body relative to the environment. This is in line with the well-documented dominance of eyecentered spatial coding in caudal PPC, that is, the modulation of neuronal activity by the distance of visual targets or acting effectors from the line of gaze (Batista et al., 1999; Cui, 2014; Medendorp et al., 2003). Moreover, spatial information is predictively updated across eye movements to maintain a stable, allocentric representation in this reference frame (Duhamel et al., 1992; Mirpour and Bisley, 2016). Finally, caudal PPC activity reflects the expected visual consequences of planned movements, suggesting that planning is initially based on body-independent specification of the intended action effects (Pilacinski et al., 2018). Note, however, that the preference for eyecentered coding is relative, rather than absolute (McGuire and Sabes, 2011; Pesaran et al., 2006). Thus, in caudal PPC, this reference frame is used not only to code visual information, but also bodyrelated information such as hand position (Batista, Buneo, Snyder, \& Andersen, 1999; Beurze et al., 2007; Beurze, Toni, Pisella, \& Medendorp, 2010; Medendorp, Goltz, Crawford, et al., 2005).

Behavioral and imaging work on tactile localization support this notion, a research area that has addressed the division into body-related and environment-related representation. For instance, identifying a limb can be error prone, and humans can confuse tactile stimuli between the two hands and even between a hand or a foot (Badde et al., 2019; Schicke and Röder, 2006; Yamamoto and Kitazawa, 2001). Also, tactile stimuli to the right hand appear to be coded as "left" - thus, in external, presumably gaze-centered space (Heed et al., 2016a) - in the environment-related pole of PPC when the hand is crossed over to the left side of space (Ruzzoli and Soto-Faraco, 2014) or when the stimulated, right-hand finger is placed left of gaze (Buchholz et al., 2013, 2011). TMS to caudal PPC disrupts the computation of this tactile external location (Azañón et al., 2010; Bolognini and Maravita, 2007). Together, these findings suggest that caudal PPC "projects" the body into the environment.

Next, our framework suggests an opposite, complementary role for rostral PPC: this region estimates the state of the body, that is, the configuration of the body and its parts, and funnels relevant, environmental information onto the body. The core function of body processing is reflected in the predominance of sensory information that is unique to the body, that is, touch, proprioception, and vestibulation. However, rostral PPC furthermore relates other sensory information, such as vision and audition, to the body, so that it codes the environment relative to the body. Accordingly, body and body-part centered reference frames dominate neural coding in rostral regions (Bremner and Andersen, 2012; Chen et al., 2013; Schlack et al., 2005; Sereno and Huang, 2006), coding environmental events with respect to that body part's current position (Heed, Buchholz, Engel, \& Röder, 2015). For instance, VIP neurons appear to code visual stimuli relative to their tactile receptive field (Duhamel et al., 1998; Graziano and Cooke, 2006). Thus, rostral PPC recodes, or maps, sensory information onto the body in a format that is highly compatible with the coding requirements for motor action and sensorimotor control loops. The proposed role of rostral PPC in body state estimation is consistent with studies that have observed $\mathrm{fMRI}$ activation related to body posture in rostral PPC, both in the context of sensorimotor tasks (Parkinson et al., 2010; Pellijeff et al., 2006) as well as during observation of hand actions (Zimmermann et al., 2013). Likewise, it is supported by the report about a patient who, after a lesion located presumably in SPL, lost the ability to keep track of her arm's postural state (Wolpert et al., 1998).

In effect, both rostral and caudal PPC serve the same underlying function, namely, to relate body and environment, but the two poles employ opposite perspectives. A rostral-to-caudal gradient for state estimation in PPC is in line with multiple studies that contrast the two poles of PPC. In the context of reach planning, caudal region PRR uses predominately eye-centered coding, whereas rostral region $5 \mathrm{~d}$ employs hand-centered coding (Beurze et al., 2010; Bremner and Andersen, 2012; Buneo et al., 2002). In fact, temporal evolution from representing the hand relative to the eye before, and the target relative to the hand after, reach target presentation has been suggested to reflect the process of state estimation for the hand during reach planning (Bremner and Andersen, 2014), in line with our proposed scheme. Furthermore, monkeys with PPC lesions located in rostral areas $5,7 b$, and MIP are unable to reach in the dark, that is, when they have to rely on proprioceptive information (Rushworth et al., 1997); in contrast, they perform successfully in the light, that is, when they can rely on visual information alone. The opposite behavioral pattern is observed in monkeys with lesions in caudal PPC areas LIP and 7a, suggesting that they 
cannot relate their movements to visual information. Similarly, prism-induced reaching errors relating to the hand movement evoked adaptive neuronal activity in monkey area 5, whereas errors relating to the reach target evoked adaptive activity in area 7 (Inoue and Kitazawa, 2018).

The PPC gradient for state estimation also accommodates the observed processing during movement planning with different limbs. Common activity in caudal PPC, independent of whether the participant will move eyes, hand, or foot, suggests that stimulus evaluation proceeds disregarding its concrete realization by a particular body movement (Heed et al., 2016b). Limb-specific coding, evident only in rostral PPC, may be realized by routing limb-unspecific information from caudal PPC to limb-specific, rostral regions (Heed et al., 2016 b, 2011). Our proposal is also consistent with the functional organization of PPC suggested on the basis of microstimulation (Stepniewska et al., 2005), cytoarchitectonic segregation (Richter et al. 2019), anatomical and functional connectivity (Hadjidimitrakis et al. 2019), and action observation (Orban, 2016).

\subsection{A medial-to-lateral gradient for action classes}

We have, so far, concentrated on only one dimension - from rostral to caudal - of the posterior parietal cortical sheet. We suspect that the second dimension, a medial-to-lateral gradient, is dominated by action classes. The homuncular organization of the primary motor and premotor cortex has been radically reinterpreted based on the occurrence of functionally distinct movements that can involve multiple limbs (Stepniewska et al., 2005; Graziano and Aflalo, 2007; Graziano, 2016). Computational modelling has suggested that the organization of premotor regions may emerge as the layout that minimizes projections for each effector (Graziano and Aflalo, 2007). Although comparable modeling work has not been performed for PPC, the distribution of regions mediating observation of multi-limb movements in humans and multi-limb movements in other species is conceptually compatible with a similar, map-like organization also in this brain region.

Such a use-dependent concept inherently explains the relatively larger size of cortical areas dedicated to extensively used limbs, such as the hand in humans, as compared to those for less important limbs, in the progression from S1 to adjacent, more caudal regions (Krubitzer, 2007). Already in S1, limbs that play an important role in the animal's behavior cover larger parts of cortex than other body parts (Krubitzer, 2007). Area 5 in SPL exhibits a strong bias for the hand, but also contains neurons responsible for the feet; the overall medial-to-lateral organization follows that of S1
(Breveglieri et al., 2008; Taoka et al., 2000). In IPS, the AIP with finger and hand selectivity is located most laterally, whereas the arm reaching-related MIP is located more medially. Results from both action observation and reaching studies have suggested some hand and foot overlap in the SPL region between the more distant lateral hand and medial foot poles (Abdollahi et al., 2013; Cunningham et al., 2013; Heed et al., 2016b, 2011). Note, the dominance of body-related criteria for the organization of cortical regions is well in line with the rostral-to-caudal body-vs.-environment gradient we propose. This topology makes the PPC very suited as a system that both selects and coordinates effectors, rather than representing, in each sub-region, one specific effector. PPC organization is less obvious in more caudal regions but appears to be dominated by functional aspects related to the interaction with the environment (Fattori et al., 2015), again consistent with our rostral-to-caudal gradient.

Taking these ideas one step further, if one considers an even wider set of effectors and functions than those in the studies reviewed here, they may as a whole be optimized according to a set of learned rules that capture statistical regularities in behavior, as seen in the gradual development of primary somatosensory cortex in postnatal developing rats (Seelke et al., 2012), and suggested by computational modelling (Laflaquière et al., 2018; Makin et al., 2013; Tenenbaum et al., 2011; Terekhov and O'Regan, 2016). In such a framework, gradients from one sensory system to another, or from world- to bodycentered state estimation emerge from the statistical relationships between the respective driving forces.

\subsection{PPC flexibly interfaces sensory information} with action

So far, we have described PPC as a region that merges sensory and motor information. However, a defining aspect of PPC and of the circuits it builds with frontal cortex (Vijayakumar et al. 2018) is a role in action selection, presumably implemented as a continuous competition between goal or action alternatives (Cisek and Kalaska, 2010; Pezzulo and Cisek, 2016; Stepniewska et al., 2011). Decisions between available alternatives require that the brain evaluates and prioritizes potential actions towards them (Bisley and Mirpour, 2019; Sugrue et al., 2004) based on their expected value as well as their associated cost, such as energy consumption and danger to the body. This requirement links back to perceptual aspects of PPC function and the concept of saliency maps that spatially integrate multiple stimulus-related characteristics (Gottlieb, 2007). Thus, again PPC exhibits hybrid functionality that can be accentuated as pertaining to perception or action. 
However, a critical ability of intelligent behavior is the flexible linking between sensory information and action. For instance, the spatial coding in PPC is dynamic (Cappadocia et al., 2017), and adapts to the present task context (Bernier and Grafton, 2010; Leoné et al., 2015). For instance, a graspingrelated region in the anterior IPS exhibited gazecentered coding for visually, but body-centered coding for somaesthetically-defined grasp targets (Leoné et al., 2015). However, beyond the role of PPC in matching spatial information to body and world, several lines of work have demonstrated that PPC can abstract from spatial information, for instance by categorizing sensory input (Freedman and Assad, 2011; Freedman and Ibos, 2018) and deriving spatial relationships (Chafee et al., 2007; Chafee and Crowe, 2013; Chivukula et al., 2019), and flexibly link sensory cues to arbitrary responses (Oristaglio et al., 2006; Stoet and Snyder, 2004). This ability of interfacing perception with action is usually referred to as (top-down) taskdependence, cognitive set, or even more broadly as cognition.

But how, then, can task-dependence fit into our proposed 2-dimensional organizational scheme? There is ongoing debate about whether decisionrelated signals in PPC reflect genuine decision formation, or information originating from other regions, for instance prefrontal cortex and the basal ganglia (Crowe et al., 2013; Erlich et al., 2015; Katz et al., 2016). A framework in which PPC primarily receives decision information fits well with a role in state estimation, that is, supporting the here-and-now for whichever goal has been defined. For example, it is noteworthy that the more caudal area PRR has been reported to show activity related to several potential reach targets, whereas more rostral area $5 \mathrm{~d}$ appears to code only the finally selected reach plan (Cui \& Andersen, 2011). This increasing selectivity pertaining to the definition of an effector-action goal pair is consistent with the increasing effector-specificity from caudal to rostral, as discussed above (Heed et al., 2016b; Leoné et al., 2014a). In our view, then, task-dependence represents the conglomerate of sensorimotor functions we have discussed so far, completed by top-down control from other, presumably frontal regions. This implies that action selection and action specification proceed based on state estimation, which encompasses (multi)sensory information about the body, about the environment, and top-down regulated behavioral requirements. As a consequence, task-specific activity should be subordinate to our proposed rostro-caudal and medio-lateral gradients. Accordingly, task-specific activity should be observable all across PPC, depending on whether, for instance, the present situation requires bodyrelated or environment-directed function, and depending on which body parts the present task implies.

Indeed, quite regularly, effector choice and definition of present action alternatives depend largely, if not entirely on the task. For instance, when we are carrying a heavy box with two hands, we will not attempt to catch a ball that is thrown towards us. You won't catch a ball with your foot, and cannot swipe away an insect on the arm with that same arm. Task-context determines whether an available behavioral option is viewed as a viable alternative or not. These very simple examples show how intertwined sensory, motor, and cognitive aspects are, and demonstrate the feasibility of their common implementation in one common brain structure. State estimation subsumes all these aspects under a common roof, and may, thus, serve as an overarching theoretical construct along which PPC function can be described.

\section{Concluding remarks and future directions}

Posterior parietal function emerges from the interplay of sensory and motor functions. We propose that its main role is the estimation of the state of body and environment in the current task context. More specifically, the two poles of PPC reflect opposite requirements of state estimation that relate to choosing actions by assessing current options in the environment, and to specifying actions by optimizing body-environment interactions. According to this view, the separation into perceptual and action-related functions and their relative dominance should step in the background in attempts to understand the PPC, as they are ultimately two sides of the same coin.

As one concrete example, PPC is known to play a role in the representation of the peripersonal space (Cléry et al., 2015; Graziano and Cooke, 2006). It has recently been pointed out that the definition of this concept is inconsistent across the literature (Bufacchi and lannetti, 2018). A sensory aspect of peripersonal space is the existence of receptive fields that feature tactile RFs and, at the same time, visual RFs that extend more or less far around their tactile counterpart (Cléry et al., 2018; Duhamel et al., 1998; Graziano and Cooke, 2006). A motor aspect of peripersonal space is that electrical stimulation of the regions containing the bimodal RF evokes defensive movements (Cooke et al., 2003; Graziano et al., 2002). An integrative view in which separation of sensory and motor aspects no longer takes a prominent role is one in which both sensory and motor characteristics are viewed together to derive multiple functional roles they might support (Bufacchi and lannetti, 2018).

Our framework challenges previous concepts of distinctions that may be relevant to PPC and we expect that re-focusing in this way will lead to new 
research questions, such as how the specific sensory connections of a particular area enable different functions, on the one hand through taskspecific weighting of the different inputs, and on the other hand through anatomical, but also - and possibly predominately - functional connectivity with output-related regions (Battaglia-Mayer and Caminiti, 2019). Also, how do the specific sensory connections of a particular area enable different state estimates? How flexible are the connections between the body-related and environmentrelated state estimates? If neurons in a given state code for multiple effectors, how is a choice between them mediated? Do dynamic changes in neural coding support integration of body and environment poles, and if so, how? Incidentally, our framework also challenges current models of motor control, which at present conceptualize state estimation as a singular functional unit (Shadmehr and Krakauer, 2008), and suggests that revisions of motor control models should account for the two poles of body vs. environment. Such a revision could potentially merge other theoretical concepts about body representation, such as an action-related body schema, into motor control models (Martel et al., 2019, 2017).

The overall explanandum is how PPC estimates the state of body and environment, contributes to choosing the next best action, and supports optimal control of its execution. Future work will have to integrate behavioral function, competitive decision-making, and effector-specificity into a new concept of task-dependent action representation to address this goal.

\section{Funding}

TH acknowledges support through DFG Emmy Noether grant He 6368/1-1, 1-2, 1-3. WPM received support from the Netherlands Organisation for Scientific Research (NWO-VICl: 453-11-001).

\section{References}

Abdollahi, R.O., Jastorff, J., Orban, G.A., 2013. Common and Segregated Processing of Observed Actions in Human SPL. Cereb. Cortex 23, 2734-2753. https://doi.org/10.1093/cercor/bhs264

Aflalo, T., Kellis, S., Klaes, C., Lee, B., Shi, Y., Pejsa, K., Shanfield, K., Hayes-Jackson, S., Aisen, M., Heck, C., Liu, C., Andersen, R.A., 2015. Decoding motor imagery from the posterior parietal cortex of a tetraplegic human. Science 348, 906-910. https://doi.org/10.1126/science.aaa5417

Andersen, R.A., Cui, H., 2009. Intention, Action Planning, and Decision Making in Parietal-Frontal Circuits. Neuron 63, 568-583. https://doi.org/10.1016/j.neuron.2009.08.028

Azañón, E., Longo, M.R., Soto-Faraco, S., Haggard, P., 2010. The posterior parietal cortex remaps touch into external space. Curr. Biol. 20, 1304-1309. https://doi.org/10.1016/j.cub.2010.05.063

Badde, S., Röder, B., Heed, T., 2019. Feeling a Touch to the Hand on the Foot. Curr. Biol. 0.

https://doi.org/10.1016/j.cub.2019.02.060

Bakker, M., De Lange, F.P., Helmich, R.C., Scheeringa, R., Bloem, B.R., Toni, I., 2008. Cerebral correlates of motor imagery of normal and precision gait. Neurolmage 41, 998-1010.

https://doi.org/10.1016/j.neuroimage.2008.03.020

Bakola, S., Gamberini, M., Passarelli, L., Fattori, P., Galletti, C., 2010. Cortical Connections of Parietal Field PEc in the Macaque: Linking Vision and Somatic Sensation for the Control of Limb Action. Cereb. Cortex 20, 2592-2604. https://doi.org/10.1093/cercor/bhq007

Baldwin, M.K.L., Cooke, D.F., Krubitzer, L., 2016. Intracortical Microstimulation Maps of Motor, Somatosensory, and Posterior Parietal Cortex in Tree Shrews ( Tupaia belangeri) Reveal Complex Movement Representations. Cereb. Cortex bhv329. https://doi.org/10.1093/cercor/bhv329

Batista, A.P., Buneo, C.A., Snyder, L.H., Andersen, R.A., 1999. Reach plans in eye-centered coordinates. Science 285, 257-260. https://doi.org/10.1126/science.285.5425.257

Battaglia-Mayer, A., Caminiti, R., 2019. Cortico-Cortical Systems Underlying High-Order Motor Control. J. Neurosci. 2094-18. https://doi.org/10.1523/JNEUROSCI.2094-18.2019

Bernier, P.-M., Grafton, S.T., 2010. Human posterior parietal cortex flexibly determines feference frames for reaching based on sensory context. Neuron 68, 776-788.

https://doi.org/10.1016/j.neuron.2010.11.002

Beurze, S.M., de Lange, F.P., Toni, I., Medendorp, W.P., 2009. Spatial and Effector Processing in the Human Parietofrontal Network for Reaches and Saccades. J. Neurophysiol. 101, 30533062. https://doi.org/10.1152/jn.91194.2008

Beurze, S.M., de Lange, F.P., Toni, I., Medendorp, W.P., 2007. Integration of Target and Effector Information in the Human Brain During Reach Planning. J. Neurophysiol. 97, 188-199.

https://doi.org/10.1152/jn.00456.2006

Beurze, S.M., Toni, I., Pisella, L., Medendorp, W.P., 2010. Reference Frames for Reach Planning in Human Parietofrontal Cortex. J. Neurophysiol. 104, 1736-1745.

https://doi.org/10.1152/jn.01044.2009

Bisley, J.W., Mirpour, K., 2019. The neural instantiation of a priority map. Curr. Opin. Psychol., Attention \& Perception 29, 108-112. https://doi.org/10.1016/j.copsyc.2019.01.002

Bolognini, N., Maravita, A., 2007. Proprioceptive alignment of visual and somatosensory maps in the posterior parietal cortex. Curr. Biol. 17, 1890-1895.

https://doi.org/10.1016/j.cub.2007.09.057

Bremner, L.R., Andersen, R.A., 2014. Temporal Analysis of Reference Frames in Parietal Cortex Area 5d during Reach Planning. J. Neurosci. 34, 5273-5284.

https://doi.org/10.1523/JNEUROSCI.2068-13.2014

Bremner, L.R., Andersen, R.A., 2012. Coding of the Reach Vector in Parietal Area 5d. Neuron 75, 342-351. https://doi.org/10.1016/j.neuron.2012.03.041

Breveglieri, R., Galletti, C., Monaco, S., Fattori, P., 2008. Visual, Somatosensory, and Bimodal Activities in the Macaque Parietal Area PEc. Cereb. Cortex 18, 806-816. https://doi.org/10.1093/cercor/bhm127

Buchholz, V.N., Jensen, O., Medendorp, W.P., 2013. Parietal oscillations code nonvisual reach targets relative to gaze and body. J. Neurosci. 33, 3492-3499.

https://doi.org/10.1523/JNEUROSCI.3208-12.2013

Buchholz, V.N., Jensen, O., Medendorp, W.P., 2011. Multiple reference frames in cortical oscillatory activity during tactile remapping for saccades. J. Neurosci. 31, 16864-16871.

Bufacchi, R.J., Iannetti, G.D., 2018. An Action Field Theory of Peripersonal Space. Trends Cogn. Sci.

https://doi.org/10.1016/j.tics.2018.09.004

Buneo, C.A., Jarvis, M.R., Batista, A.P., Andersen, R.A., 2002. Direct visuomotor transformations for reaching. Nature 416, 632-636. https://doi.org/10.1038/416632a

Burnod, Y., Baraduc, P., Battaglia-Mayer, A., Guigon, E., Koechlin,

E., Ferraina, S., Lacquaniti, F., Caminiti, R., 1999. Parieto-frontal coding of reaching: an integrated framework. Exp. Brain Res. 129, 325-346. https://doi.org/10.1007/s002210050902

Calton, J.L., Dickinson, A.R., Snyder, L.H., 2002. Non-spatial, motorspecific activation in posterior parietal cortex. Nat. Neurosci. 5, 580-588. https://doi.org/10.1038/nn0602-862

Caminiti, R., Chafee, M.V., Battaglia-Mayer, A., Averbeck, B.B., Crowe, D.A., Georgopoulos, A.P., 2010. Understanding the parietal lobe syndrome from a neurophysiological and evolutionary 
perspective. Eur. J. Neurosci. 31, 2320-2340.

https://doi.org/10.1111/j.1460-9568.2010.07291.x

Cappadocia, D.C., Monaco, S., Chen, Y., Blohm, G., Crawford, J.D., 2017. Temporal Evolution of Target Representation, Movement Direction Planning, and Reach Execution in Occipital-ParietalFrontal Cortex: An fMRI Study. Cereb. Cortex 27, 5242-5260. https://doi.org/10.1093/cercor/bhw304

Cattaneo, L., Rizzolatti, G., 2009. The mirror neuron system. Arch. Neurol. 66, 557-560.

Chafee, M.V., Averbeck, B.B., Crowe, D.A., 2007. Representing Spatial Relationships in Posterior Parietal Cortex: Single Neurons Code Object-Referenced Position. Cereb. Cortex 17, 2914-2932. https://doi.org/10.1093/cercor/bhm017

Chafee, M.V., Crowe, D.A., 2013. Thinking in spatial terms: decoupling spatial representation from sensorimotor control in monkey posterior parietal areas 7a and LIP. Front. Integr. Neurosci. 6. https://doi.org/10.3389/fnint.2012.00112

Chang, S.W.C., Dickinson, A.R., Snyder, L.H., 2008. Limb-Specific Representation for Reaching in the Posterior Parietal Cortex. J. Neurosci. 28, 6128-6140.

https://doi.org/10.1523/JNEUROSCI.1442-08.2008

Chen, X., DeAngelis, G.C., Angelaki, D.E., 2013. Diverse spatial reference frames of vestibular signals in parietal cortex. Neuron 80 1310-1321. https://doi.org/10.1016/j.neuron.2013.09.006

Chivukula, S., Jafari, M., Aflalo, T., Yong, N.A., Pouratian, N., 2019. Cognition in Sensorimotor Control: Interfacing With the Posterior Parietal Cortex. Front. Neurosci. 13.

https://doi.org/10.3389/fnins.2019.00140

Cisek, P., Kalaska, J.F., 2010. Neural Mechanisms for Interacting with a World Full of Action Choices. Annu. Rev. Neurosci. 33, 269298. https://doi.org/10.1146/annurev.neuro.051508.135409

Cléry, J., Guipponi, O., Odouard, S., Pinède, S., Wardak, C., Hamed, S.B., 2017. The Prediction of Impact of a Looming Stimulus onto the Body Is Subserved by Multisensory Integration Mechanisms. J. Neurosci. 37, 10656-10670.

https://doi.org/10.1523/JNEUROSCI.0610-17.2017

Cléry, J., Guipponi, O., Odouard, S., Wardak, C., Ben Hamed, S., 2018. Cortical networks for encoding near and far space in the nonhuman primate. Neurolmage 176, 164-178.

https://doi.org/10.1016/j.neuroimage.2018.04.036

Cléry, J., Guipponi, O., Wardak, C., Ben Hamed, S., 2015. Neuronal bases of peripersonal and extrapersonal spaces, their plasticity and their dynamics: Knowns and unknowns. Neuropsychologia 70, 313326. https://doi.org/10.1016/j.neuropsychologia.2014.10.022

Connolly, J.D., Goodale, M.A., Desouza, J.F.X., Menon, R.S., Vilis, T., 2000. A Comparison of Frontoparietal fMRI Activation During AntiSaccades and Anti-Pointing. J. Neurophysiol. 84, 1645-1655.

Cooke, D.F., Taylor, C.S.R., Moore, T., Graziano, M.S.A., 2003. Complex movements evoked by microstimulation of the ventral intraparietal area. Proc. Natl. Acad. Sci. U. S. A. 100, 6163-6168. https://doi.org/10.1073/pnas.1031751100

Corbetta, M., Akbudak, E., Conturo, T.E., Snyder, A.Z., Ollinger, J.M., Drury, H.A., Linenweber, M.R., Petersen, S.E., Raichle, M.E., Van Essen, D.C., Shulman, G.L., 1998. A Common Network of Functional Areas for Attention and Eye Movements. Neuron 21, 761-773. https://doi.org/10.1016/S0896-6273(00)80593-0

Crawford, J.D., Henriques, D.Y.P., Medendorp, W.P., 2011. Threedimensional transformations for goal-directed action. Annu. Rev. Neurosci. 34, 309-331. https://doi.org/10.1146/annurev-neuro061010-113749

Crowe, D.A., Goodwin, S.J., Blackman, R.K., Sakellaridi, S.,

Sponheim, S.R., lii, A.W.M., Chafee, M.V., 2013. Prefrontal neurons transmit signals to parietal neurons that reflect executive control of cognition. Nat. Neurosci. 16, 1484-1491.

https://doi.org/10.1038/nn.3509

Cui, H., 2014. From Intention to Action: Hierarchical Sensorimotor Transformation in the Posterior Parietal Cortex. eNeuro 1. https://doi.org/10.1523/ENEURO.0017-14.2014

Cunningham, D.A., Machado, A., Yue, G.H., Carey, J.R., Plow, E.B., 2013. Functional somatotopy revealed across multiple cortical regions using a model of complex motor task. Brain Res. 1531, 2536. https://doi.org/10.1016/j.brainres.2013.07.050

Diedrichsen, J., Shadmehr, R., Ivry, R.B., 2010. The coordination of movement: optimal feedback control and beyond. Trends Cogn. Sci. 14, 31-39. https://doi.org/10.1016/j.tics.2009.11.004
Duhamel, Colby, C.L., Goldberg, M.E., 1992. The updating of the representation of visual space in parietal cortex by intended eye movements. Science 255, 90-92.

https://doi.org/10.1126/science.1553535

Duhamel, J.-R., Colby, C.L., Goldberg, M.E., 1998. Ventral intraparietal area of the macaque: congruent visual and somatic response properties. J. Neurophysiol. 79, 126-136.

Erlich, J.C., Brunton, B.W., Duan, C.A., Hanks, T.D., Brody, C.D., 2015. Distinct effects of prefrontal and parietal cortex inactivations on an accumulation of evidence task in the rat. elife 4. https://doi.org/10.7554/eLife.05457

Fattori, P., Breveglieri, R., Bosco, A., Gamberini, M., Galletti, C., 2015. Vision for Prehension in the Medial Parietal Cortex. Cereb. Cortex bhv302. https://doi.org/10.1093/cercor/bhv302

Fernandez-Ruiz, J., Goltz, H.C., DeSouza, J.F.X., Vilis, T., Crawford, J.D., 2007. Human Parietal "Reach Region" Primarily Encodes Intrinsic Visual Direction, Not Extrinsic Movement Direction, in a Visual-Motor Dissociation Task. Cereb. Cortex 17, 2283-2292. https://doi.org/10.1093/cercor/bhl137

Filimon, F., Nelson, J.D., Hagler, D.J., Sereno, M.I., 2007. Human cortical representations for reaching: Mirror neurons for execution, observation, and imagery. Neurolmage 37, 1315-1328. https://doi.org/10.1016/j.neuroimage.2007.06.008

Freedman, D.J., Assad, J.A., 2011. A proposed common neural mechanism for categorization and perceptual decisions. Nat Neurosci 14, 143-146. https://doi.org/10.1038/nn.2740 Freedman, D.J., Ibos, G., 2018. An Integrative Framework for Sensory, Motor, and Cognitive Functions of the Posterior Parietal Cortex. Neuron 97, 1219-1234.

https://doi.org/10.1016/j.neuron.2018.01.044

Fusi, S., Miller, E.K., Rigotti, M., 2016. Why neurons mix: high dimensionality for higher cognition. Curr. Opin. Neurobiol. 37, 6674. https://doi.org/10.1016/j.conb.2016.01.010

Gail, A., Andersen, R.A., 2006. Neural Dynamics in Monkey Parietal Reach Region Reflect Context-Specific Sensorimotor

Transformations. J. Neurosci. 26, 9376-9384. https://doi.org/10.1523/JNEUROSCI.1570-06.2006

Gallivan, J.P., McLean, D.A., Smith, F.W., Culham J.C., 2011. Decoding Effector-Dependent and Effector-Independent Movement Intentions from Human Parieto-Frontal Brain Activity. J. Neurosci. 31, 17149-17168.

https://doi.org/10.1523/JNEUROSCI.1058-11.2011

Gallivan, J.P., McLean, D.A., Flanagan, J.R., Culham, J.C., 2013. Where One Hand Meets the Other: Limb-Specific and ActionDependent Movement Plans Decoded from Preparatory Signals in Single Human Frontoparietal Brain Areas. J. Neurosci. 33, 19912008. https://doi.org/10.1523/JNEUROSCI.0541-12.2013

Gottlieb, J., 2007. From Thought to Action: The Parietal Cortex as a Bridge between Perception, Action, and Cognition. Neuron 53, 916. https://doi.org/10.1016/j.neuron.2006.12.009

Gottlieb, J., Balan, P., 2010. Attention as a decision in information space. Trends Cogn. Sci. 14, 240-248.

https://doi.org/10.1016/j.tics.2010.03.001

Graziano, M.S.A., 2016. Ethological Action Maps: A Paradigm Shift for the Motor Cortex. Trends Cogn. Sci. 20, 121-132. https://doi.org/10.1016/j.tics.2015.10.008

Graziano, M.S.A., Aflalo, T.N., 2007. Mapping Behavioral Repertoire onto the Cortex. Neuron 56, 239-251.

https://doi.org/10.1016/j.neuron.2007.09.013

Graziano, M.S.A., Cooke, D.F., 2006. Parieto-frontal interactions, personal space, and defensive behavior. Neuropsychologia 44, 845-859. https://doi.org/10.1016/j.neuropsychologia.2005.09.009 Graziano, M.S.A., Taylor, C.S.R., Moore, T., 2002. Complex Movements Evoked by Microstimulation of Precentral Cortex. Neuron 34, 841-851. https://doi.org/10.1016/S08966273(02)00698-0

Grefkes, C., Fink, G.R., 2005. The functional organization of the intraparietal sulcus in humans and monkeys. J. Anat. 207, 3-17. https://doi.org/10.1111/j.1469-7580.2005.00426.x

Grill-Spector, K., Malach, R., 2001. fMR-adaptation: a tool for studying the functional properties of human cortical neurons. Acta Psychol. (Amst.) 107, 293-321. https://doi.org/10.1016/S00016918(01)00019-1

Guipponi, O., Wardak, C., Ibarrola, D., Comte, J.-C., SappeyMarinier, D., Pinede, S., Ben Hamed, S., 2013. Multimodal 
Convergence within the Intraparietal Sulcus of the Macaque Monkey. J. Neurosci. 33, 4128-4139.

https://doi.org/10.1523/JNEUROSCI.1421-12.2013

Hagler Jr., D.J., Riecke, L., Sereno, M.I., 2007. Parietal and superior frontal visuospatial maps activated by pointing and saccades. Neurolmage 35, 1562-1577.

https://doi.org/10.1016/j.neuroimage.2007.01.033

Hardwick, R.M., Caspers, S., Eickhoff, S.B., Swinnen, S.P., 2018. Neural correlates of action: Comparing meta-analyses of imagery observation, and execution. Neurosci. Biobehav. Rev. 94, 31-44. https://doi.org/10.1016/j.neubiorev.2018.08.003

Heed, T., Backhaus, J., Röder, B., Badde, S., 2016a. Disentangling the External Reference Frames Relevant to Tactile Localization. PLOS ONE 11, e0158829.

https://doi.org/10.1371/journal.pone.0158829

Heed, T., Beurze, S.M., Toni, I., Röder, B., Medendorp, W.P., 2011. Functional Rather than Effector-Specific Organization of Human Posterior Parietal Cortex. J Neurosci 31, 3066-3076. https://doi.org/10.1523/JNEUROSCI.4370-10.2011

Heed, T., Leone, F.T.M., Toni, I., Medendorp, W.P., 2016b. Functional versus effector-specific organization of the human posterior parietal cortex: revisited. J. Neurophysiol. 116, 18851899. https://doi.org/10.1152/jn.00312.2014

Hinkley, L.B.N., Krubitzer, L.A., Padberg, J., Disbrow, E.A., 2009 Visual-Manual Exploration and Posterior Parietal Cortex in Humans. J. Neurophysiol. 102, 3433-3446. https://doi.org/10.1152/jn.90785.2008

Huang, R.-S., Chen, C. -f., Tran, A.T., Holstein, K.L., Sereno, M.I., 2012. Mapping multisensory parietal face and body areas in humans. Proc. Natl. Acad. Sci.

https://doi.org/10.1073/pnas.1207946109

Huntenburg, J.M., Bazin, P.-L., Margulies, D.S., 2018. Large-Scale Gradients in Human Cortical Organization. Trends Cogn. Sci. 22, 21-31. https://doi.org/10.1016/j.tics.2017.11.002

Inoue, M., Kitazawa, S., 2018. Motor Error in Parietal Area 5 and Target Error in Area 7 Drive Distinctive Adaptation in Reaching. Curr. Biol. 28, 2250-2262.e3.

https://doi.org/10.1016/j.cub.2018.05.056

Jastorff, J., Begliomini, C., Fabbri-Destro, M., Rizzolatti, G., Orban, G.A., 2010. Coding Observed Motor Acts: Different Organizational Principles in the Parietal and Premotor Cortex of Humans. J. Neurophysiol. 104, 128-140.

https://doi.org/10.1152/jn.00254.2010

Kastner, S., Chen, Q., Jeong, S.K., Mruczek, R.E.B., 2017. A brief comparative review of primate posterior parietal cortex: A novel hypothesis on the human toolmaker. Neuropsychologia. https://doi.org/10.1016/j.neuropsychologia.2017.01.034 Katz, L.N., Yates, J.L., Pillow, J.W., Huk, A.C., 2016. Dissociated functional significance of decision-related activity in the primate dorsal stream. Nature 535, 285-288.

https://doi.org/10.1038/nature18617

Klaes, C., Kellis, S., Aflalo, T., Lee, B., Pejsa, K., Shanfield, K., HayesJackson, S., Aisen, M., Heck, C., Liu, C., Andersen, R.A., 2015. Hand Shape Representations in the Human Posterior Parietal Cortex. J. Neurosci. 35, 15466-15476.

https://doi.org/10.1523/JNEUROSCI.2747-15.2015

Klaes, C., Westendorff, S., Chakrabarti, S., Gail, A., 2011. Choosing Goals, Not Rules: Deciding among Rule-Based Action Plans. Neuron 70, 536-548. https://doi.org/10.1016/j.neuron.2011.02.053

Konen, C.S., Kastner, S., 2008. Representation of Eye Movements and Stimulus Motion in Topographically Organized Areas of Human Posterior Parietal Cortex. J. Neurosci. 28, 8361-8375. https://doi.org/10.1523/JNEUROSCI.1930-08.2008

Krakauer, J.W., Ghazanfar, A.A., Gomez-Marin, A., Maclver, M.A., Poeppel, D., 2017. Neuroscience Needs Behavior: Correcting a Reductionist Bias. Neuron 93, 480-490. https://doi.org/10.1016/j.neuron.2016.12.041 Krubitzer, L., 2007. The Magnificent Compromise: Cortical Field Evolution in Mammals. Neuron 56, 201-208. https://doi.org/10.1016/j.neuron.2007.10.002

Laflaquière, A., O'Regan, J.K., Gas, B., Terekhov, A., 2018. Discovering space - Grounding spatial topology and metric regularity in a naive agent's sensorimotor experience. Neural Netw. 105, 371-392.

https://doi.org/10.1016/j.neunet.2018.06.001
Leoné, F.T.M., Heed, T., Toni, I., Medendorp, W.P., 2014a. Understanding Effector Selectivity in Human Posterior Parietal Cortex by Combining Information Patterns and Activation Measures. J. Neurosci. 34, 7102-7112. https://doi.org/10.1523/JNEUROSCI.5242-13.2014 Leoné, F.T.M., Monaco, S., Henriques, D.Y.P., Toni, I., Medendorp, W.P., 2015. Flexible Reference Frames for Grasp Planning in Human Parietofrontal Cortex. eneuro 2, ENEURO.0008-15.2015. https://doi.org/10.1523/ENEURO.0008-15.2015 Leoné, F.T.M., Toni, I., Medendorp, W.P., 2014b. Two-dimensional spatial tuning for saccades in human parieto-frontal cortex. Neurolmage 87, 476-489.

https://doi.org/10.1016/j.neuroimage.2013.09.067

Levy, I., Schluppeck, D., Heeger, D.J., Glimcher, P.W., 2007. Specificity of Human Cortical Areas for Reaches and Saccades. J. Neurosci. 27, 4687-4696. https://doi.org/10.1523/JNEUROSCI.0459-07.2007 Lorey, B., Naumann, T., Pilgramm, S., Petermann, C., Bischoff, M., Zentgraf, K., Stark, R., Vaitl, D., Munzert, J., 2014. Neural simulation of actions: Effector- versus action-specific motor maps within the human premotor and posterior parietal area? Hum. Brain Mapp. 35, 1212-1225. https://doi.org/10.1002/hbm.22246

Makin, J.G., Fellows, M.R., Sabes, P.N., 2013. Learning multisensory integration and coordinate transformation via density estimation. PLoS Comput. Biol. 9, e1003035.

https://doi.org/10.1371/journal.pcbi.1003035

Mars, R.B., Jbabdi, S., Sallet, J., O'Reilly, J.X., Croxson, P.L., Olivier,

E., Noonan, M.P., Bergmann, C., Mitchell, A.S., Baxter, M.G., Behrens, T.E.J., Johansen-Berg, H., Tomassini, V., Miller, K.L., Rushworth, M.F.S., 2011. Diffusion-Weighted Imaging Tractography-Based Parcellation of the Human Parietal Cortex and Comparison with Human and Macaque Resting-State Functional Connectivity. J. Neurosci. 31, 4087-4100.

https://doi.org/10.1523/JNEUROSCI.5102-10.2011

Mars, R.B., Passingham, R.E., Jbabdi, S., 2018. Connectivity Fingerprints: From Areal Descriptions to Abstract Spaces. Trends Cogn. Sci. https://doi.org/10.1016/j.tics.2018.08.009

Martel, M., Cardinali, L., Bertonati, G., Jouffrais, C., Finos, L., Farnè, A., Roy, A.C., 2019. Somatosensory-guided tool use modifies arm representation for action. Sci. Rep. 9. https://doi.org/10.1038/s41598-019-41928-1

Martel, M., Cardinali, L., Roy, A.C., Farnè, A., 2017. Tool-use unravels body morphology representation in the brain, in: de Vignemont, F., Alsmith, A.J.T. (Eds.), The Subject's Matter: SelfConsciousness and the Body.

McGuire, L.M.M., Sabes, P.N., 2011. Heterogeneous Representations in the Superior Parietal Lobule Are Common across Reaches to Visual and Proprioceptive Targets. J. Neurosci.

31, 6661-6673. https://doi.org/10.1523/JNEUROSCI.2921-10.2011 Medendorp, W.P., Goltz, H.C., Crawford, J.D., Vilis, T., 2005. Integration of Target and Effector Information in Human Posterior Parietal Cortex for the Planning of Action. J. Neurophysiol. 93, 954962. https://doi.org/10.1152/jn.00725.2004

Medendorp, W.P., Goltz, H.C., Vilis, T., Crawford, J.D., 2003. GazeCentered Updating of Visual Space in Human Parietal Cortex. J. Neurosci. 23, 6209-6214

Menz, V.K., Schaffelhofer, S., Scherberger, H., 2015.

Representation of continuous hand and arm movements in macaque areas M1, F5, and AIP: a comparative decoding study. J. Neural Eng. 12, 056016. https://doi.org/10.1088/17412560/12/5/056016

Mirpour, K., Bisley, J.W., 2016. Remapping, Spatial Stability, and Temporal Continuity: From the Pre-Saccadic to Postsaccadic Representation of Visual Space in LIP. Cereb. Cortex 26, 31833195. https://doi.org/10.1093/cercor/bhv153

Mulliken, G.H., Musallam, S., Andersen, R.A., 2008. Forward estimation of movement state in posterior parietal cortex. Proc. Natl. Acad. Sci. 105, 8170-8177.

https://doi.org/10.1073/pnas.0802602105

Oostwoud Wijdenes, L., Medendorp, W.P., 2017. State Estimation for Early Feedback Responses in Reaching: Intramodal or Multimodal? Front. Integr. Neurosci. 11.

https://doi.org/10.3389/fnint.2017.00038 
Orban, G.A., 2016. Functional definitions of parietal areas in human and non-human primates. Proc R Soc B 283, 20160118. https://doi.org/10.1098/rspb.2016.0118

Oristaglio, J., Schneider, D.M., Balan, P.F., Gottlieb, J., 2006. Integration of Visuospatial and Effector Information during Symbolically Cued Limb Movements in Monkey Lateral Intraparietal Area. J. Neurosci. 26, 8310-8319. https://doi.org/10.1523/JNEUROSCI.1779-06.2006

Parkinson, A., Condon, L., Jackson, S.R., 2010. Parietal cortex coding of limb posture: In search of the body-schema. Neuropsychologia 48, 3228-3234. https://doi.org/10.1016/j.neuropsychologia.2010.06.039 Pellijeff, A., Bonilha, L., Morgan, P.S., McKenzie, K., Jackson, S.R., 2006. Parietal updating of limb posture: An event-related fMRI study. Neuropsychologia 44, 2685-2690. https://doi.org/10.1016/j.neuropsychologia.2006.01.009 Penfield, W., Boldrey, E., 1937. Somatic motor and sensory representation in the cerebral cortex of man as studied by electrical stimulation. Brain 60, 389-443. https://doi.org/10.1093/brain/60.4.389

Pesaran, B., Nelson, M.J., Andersen, R.A., 2006. Dorsal Premotor Neurons Encode the Relative Position of the Hand, Eye, and Goal during Reach Planning. Neuron 51, 125-134. https://doi.org/10.1016/j.neuron.2006.05.025

Pezzulo, G., Cisek, P., 2016. Navigating the Affordance Landscape: Feedback Control as a Process Model of Behavior and Cognition. Trends Cogn. Sci. 20, 414-424.

https://doi.org/10.1016/j.tics.2016.03.013

Pilacinski, A., Wallscheid, M., Lindner, A., 2018. Human posterior parietal and dorsal premotor cortex encode the visual properties of an upcoming action. PLOS ONE 13, e0198051.

https://doi.org/10.1371/journal.pone.0198051

Rohe, T., Noppeney, U., 2016. Distinct Computational Principles

Govern Multisensory Integration in Primary Sensory and

Association Cortices. Curr. Biol. 26, 509-514.

https://doi.org/10.1016/j.cub.2015.12.056

Roux, F., Djidjeli, I., Durand, J., 2018. Functional architecture of the somatosensory homunculus detected by electrostimulation. J. Physiol. 596, 941-956. https://doi.org/10.1113/JP275243 Rushworth, M.F.S., Nixon, P.D., Passingham, R.E., 1997. Parietal cortex and movement I. Movement selection and reaching. Exp. Brain Res. 117, 292-310. https://doi.org/10.1007/s002210050224 Ruzzoli, M., Soto-Faraco, S., 2014. Alpha stimulation of the human parietal cortex attunes tactile perception to external space. Curr. Biol. 24, 329-332. https://doi.org/10.1016/j.cub.2013.12.029 Schicke, T., Röder, B., 2006. Spatial remapping of touch: Confusion of perceived stimulus order across hand and foot. Proc. Natl. Acad. Sci. 103, 11808-11813. https://doi.org/10.1073/pnas.0601486103 Schlack, A., Sterbing-D'Angelo, S.J., Hartung, K., Hoffmann, K.-P., Bremmer, F., 2005. Multisensory space representations in the macaque ventral intraparietal area. J. Neurosci. 25, 4616-4625. https://doi.org/10.1523/JNEUROSCI.0455-05.2005

Schwartz, A.B., 2016. Movement: How the Brain Communicates with the World. Cell 164, 1122-1135.

https://doi.org/10.1016/j.cell.2016.02.038

Scott, S.H., 2012. The computational and neural basis of voluntary motor control and planning. Trends Cogn. Sci. 16, 541-549. https://doi.org/10.1016/j.tics.2012.09.008

Seelke, A.M.H., Dooley, J.C., Krubitzer, L.A., 2012. The Emergence of Somatotopic Maps of the Body in S1 in Rats: The

Correspondence Between Functional and Anatomical Organization. PLOS ONE 7, e32322.

https://doi.org/10.1371/journal.pone.0032322

Seelke, A.M.H., Padberg, J.J., Disbrow, E., Purnell, S.M., Recanzone, G., Krubitzer, L., 2011. Topographic Maps within Brodmann's Area 5 of Macaque Monkeys. Cereb. Cortex 22, 1834-1850. https://doi.org/10.1093/cercor/bhr257

Senna, I., Bolognini, N., Maravita, A., 2014. Grasping with the foot: Goal and motor expertise in action observation. Hum. Brain Mapp. 35, 1750-1760. https://doi.org/10.1002/hbm.22289 Sereno, M.I., Huang, R.-S., 2014. Multisensory maps in parietal cortex. Curr. Opin. Neurobiol. 24, 39-46. https://doi.org/10.1016/j.conb.2013.08.014
Sereno, M.I., Huang, R.-S., 2006. A human parietal face area contains aligned head-centered visual and tactile maps. Nat. Neurosci. 9, 1337-1343. https://doi.org/10.1038/nn1777 Shadmehr, R., Krakauer, J.W., 2008. A computational neuroanatomy for motor control. Exp. Brain Res. 185, 359-381. https://doi.org/10.1007/s00221-008-1280-5

Siegel, M., Buschman, T.J., Miller, E.K., 2015. Cortical information flow during flexible sensorimotor decisions. Science 348, 13521355. https://doi.org/10.1126/science.aab0551

Sirigu, A., Duhamel, J.-R., Cohen, L., Pillon, B., Dubois, B., Agid, Y., 1996. The Mental Representation of Hand Movements After Parietal Cortex Damage. Science 273, 1564-1568. https://doi.org/10.1126/science.273.5281.1564 Snyder, L.H., 2000a. Neurobiology: Moving forward by looking away. Nature 408, 921-923. https://doi.org/10.1038/35050192 Snyder, L.H., 2000b. Coordinate transformations for eye and arm movements in the brain. Curr. Opin. Neurobiol. 10, 747-754. https://doi.org/10.1016/S0959-4388(00)00152-5

Snyder, L.H., Batista, A.P., Andersen, R.A., 2000. Saccade-Related Activity in the Parietal Reach Region. J. Neurophysiol. 83, 10991102. https://doi.org/10.1152/jn.2000.83.2.1099

Snyder, L.H., Batista, A.P., Andersen, R.A., 1997. Coding of intention in the posterior parietal cortex. Nature 386, 167-170. https://doi.org/10.1038/386167a0

Stepniewska, I., Fang, P.-C., Kaas, J.H., 2005. Microstimulation reveals specialized subregions for different complex movements in posterior parietal cortex of prosimian galagos. Proc. Natl. Acad. Sci. U. S. A. $102,4878-4883$.

https://doi.org/10.1073/pnas.0501048102

Stepniewska, I., Friedman, R.M., Gharbawie, O.A., Cerkevich, C.M., Roe, A.W., Kaas, J.H., 2011. Optical imaging in galagos reveals parietal-frontal circuits underlying motor behavior. Proc. Natl. Acad. Sci. 108, E725-E732.

https://doi.org/10.1073/pnas.1109925108

Stoet, G., Snyder, L.H., 2004. Single Neurons in Posterior Parietal Cortex of Monkeys Encode Cognitive Set. Neuron 42, 1003-1012. https://doi.org/10.1016/j.neuron.2004.06.003

Sugrue, L.P., Corrado, G.S., Newsome, W.T., 2004. Matching Behavior and the Representation of Value in the Parietal Cortex. Science 304, 1782-1787. https://doi.org/10.1126/science.1094765 Szczepanski, S.M., Pinsk, M.A., Douglas, M.M., Kastner, S., Saalmann, Y.B., 2013. Functional and structural architecture of the human dorsal frontoparietal attention network. Proc. Natl. Acad. Sci. 110, 15806-15811. https://doi.org/10.1073/pnas.1313903110 Taoka, M., Toda, T., Iriki, A., Tanaka, M., Iwamura, Y., 2000. Bilateral receptive field neurons in the hindlimb region of the postcentral somatosensory cortex in awake macaque monkeys. Exp. Brain Res. 134, 139-146. https://doi.org/10.1007/s002210000464

Taoka, M., Toda, T., Iwamura, Y., 1998. Representation of the midline trunk, bilateral arms, and shoulders in the monkey postcentral somatosensory cortex. Exp. Brain Res. 123, 315-322.

Tenenbaum, J.B., Kemp, C., Griffiths, T.L., Goodman, N.D., 2011. How to Grow a Mind: Statistics, Structure, and Abstraction. Science 331, 1279-1285. https://doi.org/10.1126/science.1192788 Terekhov, A.V., O'Regan, J.K., 2016. Space as an Invention of Active Agents. Front. Robot. Al 3. https://doi.org/10.3389/frobt.2016.00004

Todorov, E., 2004. Optimality principles in sensorimotor control. Nat. Neurosci. 7, 907-915. https://doi.org/10.1038/nn1309 Vallar, G., Coslett, H.B. (Eds.), 2018. The Parietal Lobe, Handbook of Clinical Neurology. Elsevier.

Valyear, K.F., Frey, S.H., 2015. Human posterior parietal cortex mediates hand-specific planning. Neurolmage 114, 226-238. https://doi.org/10.1016/j.neuroimage.2015.03.058

Valyear, K.F., Gallivan, J.P., McLean, D.A., Culham, J.C., 2012. fMRI Repetition Suppression for Familiar But Not Arbitrary Actions with Tools. J. Neurosci. 32, 4247-4259.

Vesia, M., Crawford, J.D., 2012. Specialization of reach function in human posterior parietal cortex. Exp. Brain Res. 221, 1-18. https://doi.org/10.1007/s00221-012-3158-9

Vesia, M., Prime, S., Yan, X., Sergio, L., Crawford, J.D., 2010a. Parietal regions specialized for saccades and reach in the human: a 
rTMS study. J. Vis. 10, 1093-1093.

https://doi.org/10.1167/10.7.1093

Vesia, M., Prime, S.L., Yan, X., Sergio, L.E., Crawford, J.D., 2010b.

Specificity of Human Parietal Saccade and Reach Regions during

Transcranial Magnetic Stimulation. J. Neurosci. 30, 13053-13065.

https://doi.org/10.1523/JNEUROSCI.1644-10.2010

Vingerhoets, G., 2014. Contribution of the posterior parietal cortex

in reaching, grasping, and using objects and tools. Cognition 5, 151. https://doi.org/10.3389/fpsyg.2014.00151

Wolpert, D.M., Goodbody, S.J., Husain, M., 1998. Maintaining internal representations: the role of the human superior parietal lobe. Nat. Neurosci. 1, 529-533. https://doi.org/10.1038/2245

$\mathrm{Xu}$, Y., 2018. The Posterior Parietal Cortex in Adaptive Visual

Processing. Trends Neurosci. 41, 806-822.

https://doi.org/10.1016/j.tins.2018.07.012

Yamamoto, S., Kitazawa, S., 2001. Reversal of subjective temporal order due to arm crossing. Nat Neurosci 4, 759-765.

https://doi.org/10.1038/89559

Zhang, C.Y., Aflalo, T., Revechkis, B., Rosario, E.R., Ouellette, D. Pouratian, N., Andersen, R.A., 2017. Partially Mixed Selectivity in Human Posterior Parietal Association Cortex. Neuron 95, 697708.e4. https://doi.org/10.1016/j.neuron.2017.06.040

Zhang, M., Barash, S., 2000. Neuronal switching of sensorimotor transformations for antisaccades. Nature 408, 971-975.

https://doi.org/10.1038/35050097

Zimmermann, M., Toni, I., de Lange, F.P., 2013. Body Posture

Modulates Action Perception. J. Neurosci. 33, 5930-5938.

https://doi.org/10.1523/JNEUROSCI.5570-12.2013 